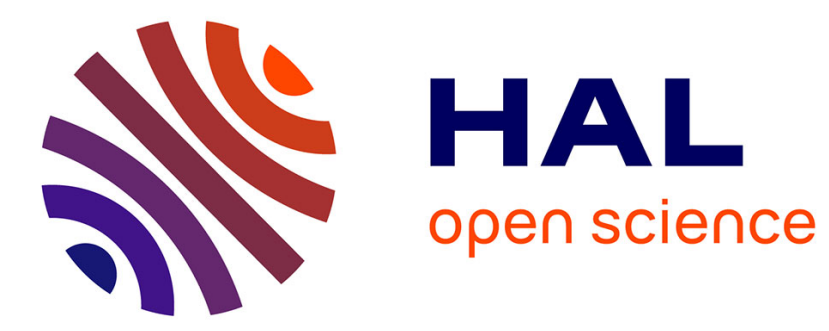

\title{
Experimental study of a pre-cracked steel-concrete composite beam
}

B. Jurkiewiez, S. Braymand

\section{To cite this version:}

B. Jurkiewiez, S. Braymand. Experimental study of a pre-cracked steel-concrete composite beam. Journal of Constructional Steel Research, 2007, 63 (1), pp.135-144. 10.1016/j.jcsr.2006.03.013 . hal00593517

\section{HAL Id: hal-00593517 \\ https://hal.science/hal-00593517}

Submitted on 22 Nov 2021

HAL is a multi-disciplinary open access archive for the deposit and dissemination of scientific research documents, whether they are published or not. The documents may come from teaching and research institutions in France or abroad, or from public or private research centers.
L'archive ouverte pluridisciplinaire HAL, est destinée au dépôt et à la diffusion de documents scientifiques de niveau recherche, publiés ou non, émanant des établissements d'enseignement et de recherche français ou étrangers, des laboratoires publics ou privés.

\section{다)(1) $(5$}

Distributed under a Creative Commons Attribution - NonCommercial| 4.0 International 


\title{
Experimental study of a pre-cracked steel-concrete composite beam
}

\author{
B. Jurkiewiez ${ }^{\mathrm{a}, *}$, S. Braymand ${ }^{\mathrm{b}, 1}$ \\ ${ }^{a}$ Université Lyon 1, L2MS, 82 boulevard Niels Bohr, F-69622 Villeurbanne cedex, France \\ ${ }^{\mathrm{b}}$ Université Robert Schuman, Départment Génie Civil, 72 route du Rhin, F-67400 Illkirch, France
}

\begin{abstract}
A steel-concrete composite beam equipped with shear studs is loaded under a monotonic bending moment until failure. The originality and the interest of this experimental study lies in two different aspects: first, the concrete slab is transversally cracked before the beginning of the test because of restrained shrinkage strains; second, the experimental set-up includes the measures of slip at the steel-concrete interface and axial strain of some studs. The first and well-known result is that the behaviour of the beam may be divided into an elastic domain and a plastic domain with a significant ductility; the failure located in the central zone originates in high compressive strain in the concrete slab followed by crushing. Furthermore, the transverse cracks induce, mainly in the elastic domain, strong discontinuities in the longitudinal distribution of the slip and a noticeable evolution of the shear stud deflection scheme in the concrete slab. Numerical simulations performed within the elastic domain, accounting for slip or not, and at the ultimate stage according to Eurocodes are in good agreement with measurements for deflection and longitudinal strains.
\end{abstract}

Keywords: Steel-concrete composite beam; Studs; Static bending test; Pre-cracked concrete slab

\section{Introduction}

Experimental results on steel-concrete composite beams are available in the literature (see for example [1-5]). Papers mainly focus on the behaviour at failure and little information is provided about the elastic domain or about the development of plastic strains. Furthermore, slip is currently measured at the end of the beam but the longitudinal distribution of slip is not often investigated in the case of a cracked slab. Strain measurements on the connection device are often lacking.

In this paper is reported a study on a steel-concrete composite beam equipped with shear studs which was subjected to an instantaneous static loading up to failure. The measurements include specific measures such as slip at the steel-concrete interface and axial strain of some shear studs.

Moreover, it must be noticed that the concrete slab was transversally cracked in five sections before the beginning of

\footnotetext{
* Corresponding author. Tel.: +33 472692130; fax: +33 478946906.

E-mail addresses: bruno.jurkiewiez@univ-lyonl.fr (B. Jurkiewiez), sandrine.braymand@urs.u-strasbg.fr (S. Braymand).

1 Tel.: +33 388676361; fax: +33 388676334 .
}

the test. These cracks resulted from the effect of restrained shrinkage strains as the beam was instrumented for 1.25 years.

The present paper is divided into three main parts. The specimens, experimental set-up and test procedures are detailed in the first part. In the second part, the main experimental results are presented and discussed. Measurements are finally compared with numerical simulations performed according to several assumptions.

\section{Presentation of the experimental study}

\subsection{Specimens casting and storage}

The beam and the test samples were cast in our laboratory with the same ready-mix self-compacting concrete (see Section 2.2). The top surface of the upper flange of the steel beam was greased before casting to eliminate natural adhesion. Seven weeks after concreting, the mould was removed and the composite beam was transferred to the instrumentation area. The age of the concrete was 1.25 years as the test was performed. During this relatively long preparation period necessary to equip the beam, the hydrothermal conditions were not measured but they were the same for all the specimens 
Table 1

Composition of concrete

\begin{tabular}{ll}
\hline Aggregates & $4 / 8$ \\
Cement & $0 / 4$ \\
Water & CPA 52.5 R \\
Mineral additions & - \\
& Liquid micronical silicafume \\
Additives & Calcite fillers \\
& Superplastifier \\
\hline
\end{tabular}

which were stored inside (approximate variations: $13-30{ }^{\circ} \mathrm{C}$ and $50 \%$ to $70 \%$ ). The temporary supports were located at the same section as the test supports.

\subsection{Materials}

A ready-mix self-compacting concrete with an aimed strength of $40 \mathrm{MPa}$ was used for all the specimens (see composition in Table 1). This type of concrete was selected because it allows one to almost totally avoid compacting which might damage the strain gages glued on shear studs. The compressive mechanical characteristics (strength and elastic modulus) and the tensile strength were determined by standard tests performed respectively on $\Phi 16 \times 32 \mathrm{~cm}$ cylindrical specimens and on $7 \times 7 \times 28 \mathrm{~cm}$ blocks.

The steel girder was an IPE 360 rolled beam with guaranteed yield strength of $235 \mathrm{MPa}$ and a failure strength of $360 \mathrm{MPa}$. Tensile tests were carried out on specimens cut out from an unused piece of the steel beam: two bars were extracted from the flange and two from the web.

The steel reinforcements of the concrete slab and the shear studs were supposed to exhibit guaranteed yield strength of $500 \mathrm{MPa}$ and $400 \mathrm{MPa}$ respectively. No tests were performed on these materials.

\subsection{Geometry of the beam and loading program}

A sketch of the beam is given in Fig. 1. Its clear span was $4.80 \mathrm{~m}$. The steel beam was connected to the $55 \times 10 \mathrm{~cm}$ reinforced concrete slab by means of Nelson shear studs $16 \mathrm{~mm}$ in diameter and $75 \mathrm{~mm}$ in height. The stud spacing was determined so as to avoid connection failure. The low amount of longitudinal reinforcements (about $0.3 \%$ of the concrete area) was chosen to increase shrinkage cracking during the curing period.

The beam was simply supported on rollers and the load was transferred to the composite beam by means of a two-point device. During the test, the vertical displacement of the jack was servo-controlled and increased with a speed of $62.5 \mu \mathrm{m} / \mathrm{s}$. The load was thus slowly applied and monotonically increased until failure after some unloading-reloading cycles in the elastic domain (see Fig. 2).

It may be noticed that, with the aim of checking the experimental set-up, two identical preliminary tests were performed on the beam before the final test with a maximum load of $20 \%$ and $40 \%$ of the ultimate load respectively.
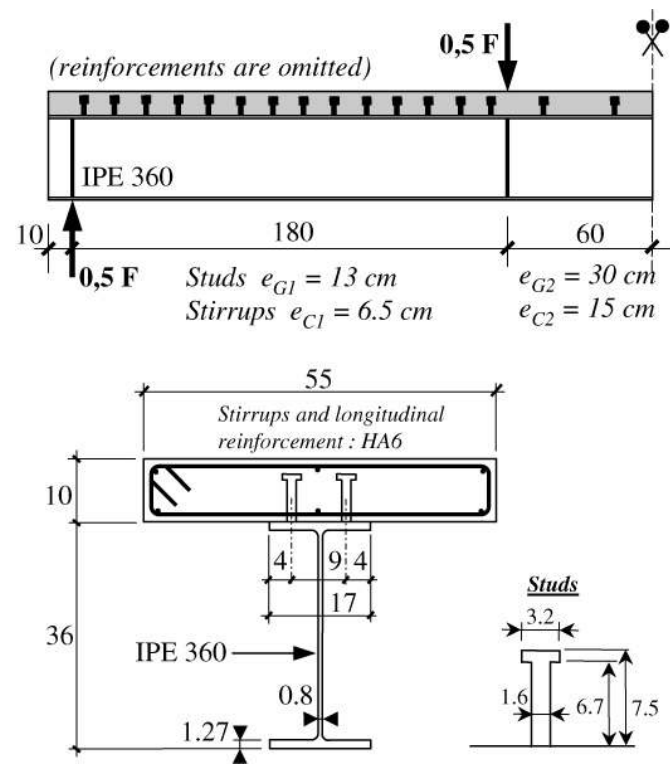

Fig. 1. Geometry and reinforcements of the beam (in $\mathrm{cm}-$ cover $=1 \mathrm{~cm}$ ).

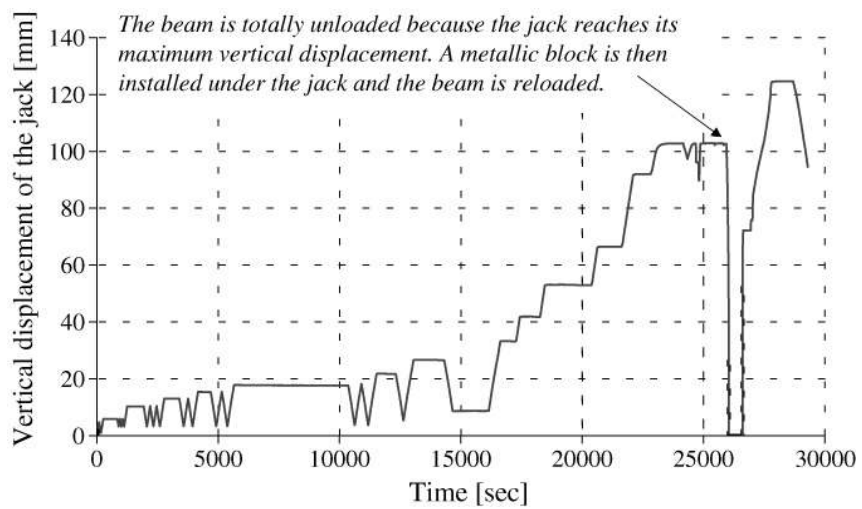

Fig. 2. Loading program.

\subsection{Instrumentation}

The measurements carried out during the bending test were the following:

- vertical displacement of the jack,

- applied load,

- deflection in five points of the lower fiber of the beam,

- longitudinal strain in the concrete slab and the steel beam in five sections,

- slip at thirteen points of the steel-concrete interface,

- axial strain at three levels of nine shear studs,

- width of the five cracks.

The ninety-six measures were numerically acquired. The experimental set-up is detailed in Figs. 3-6 and in Table 2.

\section{Experimental results}

\subsection{Main material properties characterisation}

Table 3 shows the results of tests performed on the concrete. With a compressive strength greater than $60 \mathrm{MPa}$ after 28 days 


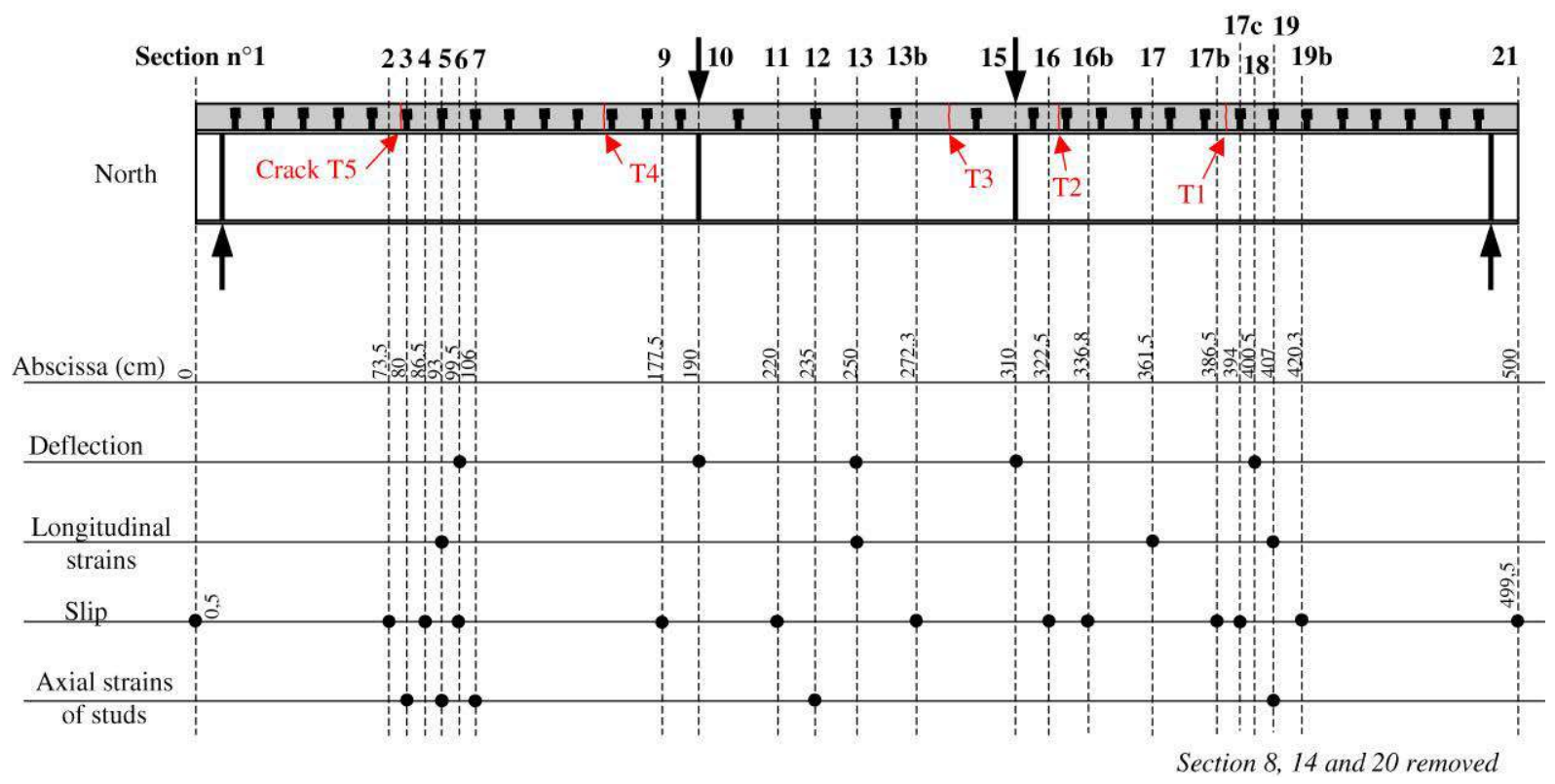

Fig. 3. Longitudinal position of the measurement sections and main transverse cracks.

Table 2

Measurement characteristics

\begin{tabular}{|c|c|c|c|}
\hline Measure & Sensor & Maximal capacity & Estimated accuracy of the measure (\%) \\
\hline Vertical displacement of the jack & LVDT $^{\mathrm{a}}$ & $250 \mathrm{~mm}$ & 0.5 \\
\hline Load & Pressure transducer & $640 \mathrm{kN}$ & 1 \\
\hline Deflection & LVDT $^{\mathrm{a}}$ & $100 \mathrm{~mm}$ & 0.1 \\
\hline Longitudinal strain in concrete slab & Strain gage & $3.5 \%(\mathrm{RL}=100 \mathrm{~mm})^{\mathrm{b}}$ & 0.5 \\
\hline Longitudinal strain in steel beam & Strain gage & $3.5 \%(\mathrm{RL}=4 \mathrm{~mm})^{\mathrm{b}}$ & 0.5 \\
\hline Slip & LVDT $^{\mathrm{a}}$ & $20 \mathrm{~mm}$ & 1 \\
\hline Uplift & LVDT $^{\mathrm{a}}$ & $10 \mathrm{~mm}$ & 0.1 \\
\hline Axial strain in shear studs & Strain gage & $0.5 \%(\mathrm{RL}=2 \mathrm{~mm})^{\mathrm{b}}$ & 0.5 \\
\hline Crack width & Specific graduated rule & $1.5 \mathrm{~mm}$ & $0.05 \mathrm{~mm}^{\mathrm{c}}$ \\
\hline
\end{tabular}

a LVDT: linear variable differential transformer.

b RL: reference length.

c Minimum reading accuracy.

Table 3

Tensile and compressive strength of the concrete

\begin{tabular}{|c|c|c|c|c|}
\hline \multirow[t]{2}{*}{ Age of concrete } & \multicolumn{2}{|c|}{ Compressive strength (MPa) } & \multicolumn{2}{|c|}{ Tensile strength (MPa) } \\
\hline & Mean value & Standard deviation & Mean value & Standard deviation \\
\hline 7 days & 48.3 & 0.5 & - & - \\
\hline 14 days & 52.2 & 0.4 & - & - \\
\hline 28 days & 60.8 & 0.6 & 3.5 & 0.2 \\
\hline 90 days & 70.0 & 0.6 & 5.0 & 0.2 \\
\hline 1 year & 75.7 & 1.0 & - & - \\
\hline 1.25 years & 76.6 & 1.0 & 5.0 & - \\
\hline
\end{tabular}

and $76 \mathrm{MPa}$ after 1 year, this concrete may be referred to as a high strength concrete; this is confirmed by its brittle behaviour observed during the compressive tests. The elastic modulus was about $33000 \mathrm{MPa}$ at 1.5 years; this low value, typical of this kind of concrete (ready-mix self-compacting concrete), was already pointed out in other studies. Furthermore, the linear elastic strain limit is graphically estimated on stress-strain curves at about $0.9 \%$.

The tensile test results related to the steel beam are presented in Table 4. The observed behaviour is a well-known elastic-plastic behaviour. The strain corresponding to the yield strength was about $1.65 \%$ and $1.35 \%$ for the web and the flange respectively; this difference may be explained by the rolling process. The average elastic modulus was about $201000 \mathrm{MPa}$. 


\section{$\underline{\text { Sections } 5,17 \text { et } 19}$}
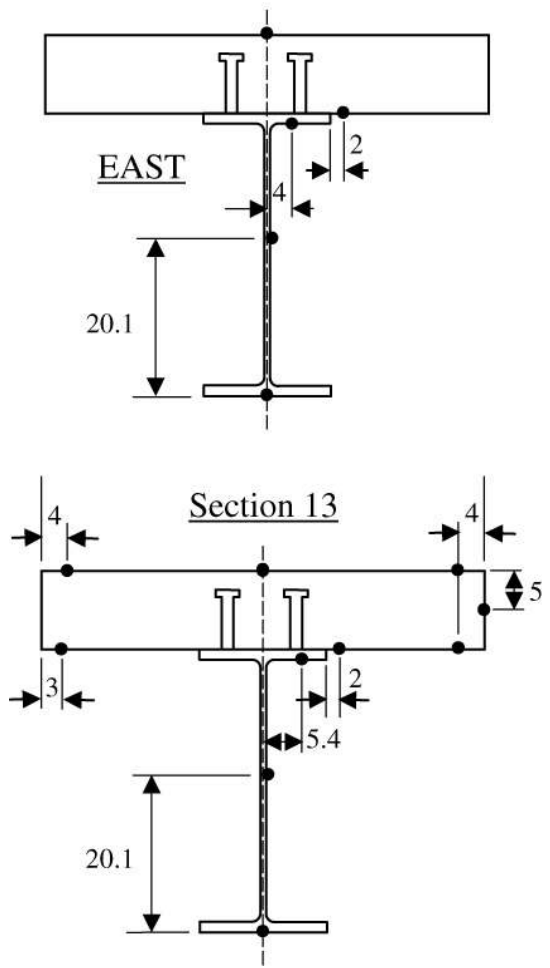

Fig. 4. Strain measurement position in concrete slab and steel beam (in $\mathrm{cm}$ ).

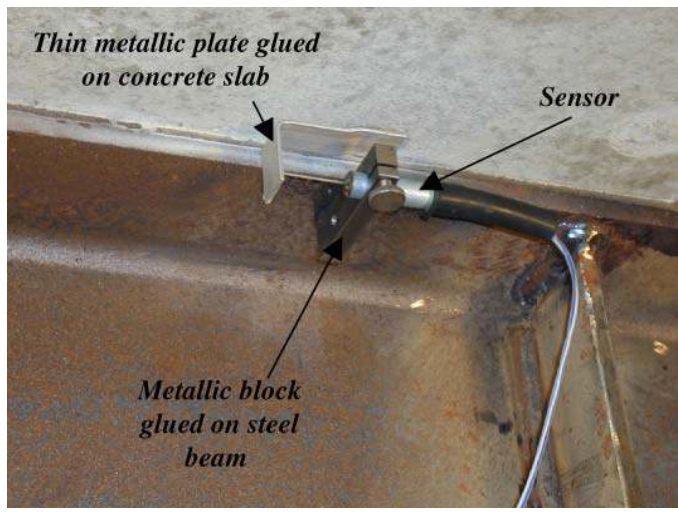

Fig. 5. Slip measurement device.

\subsection{Composite beam behaviour}

It may first be noticed that the behaviour and the measures obtained during the preliminary tests (performed within the elastic domain) were close to those of the final test. This may point out the repetition and thus the reliability of the whole experimental set-up and the results presented below.

\subsubsection{General behaviour}

As reported in the literature, the behaviour of such a composite beam may be divided into three stages: the elastic domain, the yield domain and failure (see Figs. 7-11 and Table 5). Within the elastic domain corresponding to a load lower than $300 \mathrm{kN}$, the behaviour of the beam may be regarded as almost linear and reversible. The longitudinal strains did not
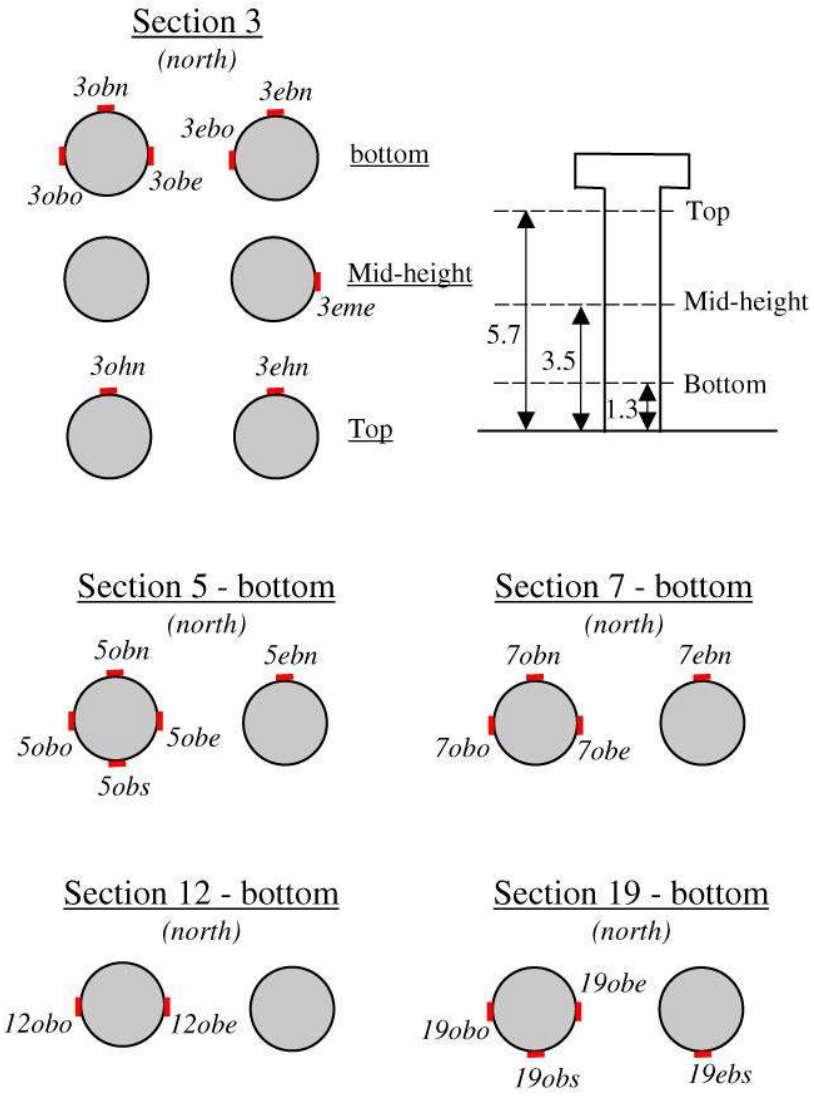

Fig. 6. Axial strain measurement position in studs (in $\mathrm{cm}$ ).

Table 4

Tensile strength of the steel beam

\begin{tabular}{lllll}
\hline Specimen & $\sigma^{\mathrm{a}}(\mathrm{MPa})$ & $\varepsilon^{\mathrm{a}}(\mu \mathrm{m} / \mathrm{m})$ & $E^{\mathrm{b}}(\mathrm{MPa})$ & $\sigma^{\mathrm{c}}(\mathrm{MPa})$ \\
\hline Web no 1 & 325.5 & 1680 & 196792 & - \\
Web no 2 & 321.8 & 1618 & 199244 & - \\
Flange no 2 & 276.2 & 1362 & 205263 & - \\
Flange no 2 & 273.5 & 1344 & 203584 & 375.6 \\
\hline
\end{tabular}

a yield stress and strain.

${ }^{b}$ elastic modulus estimated at $2 / 3 \sigma .^{a}$

$\mathrm{c}$ maximum stress (just before failure).

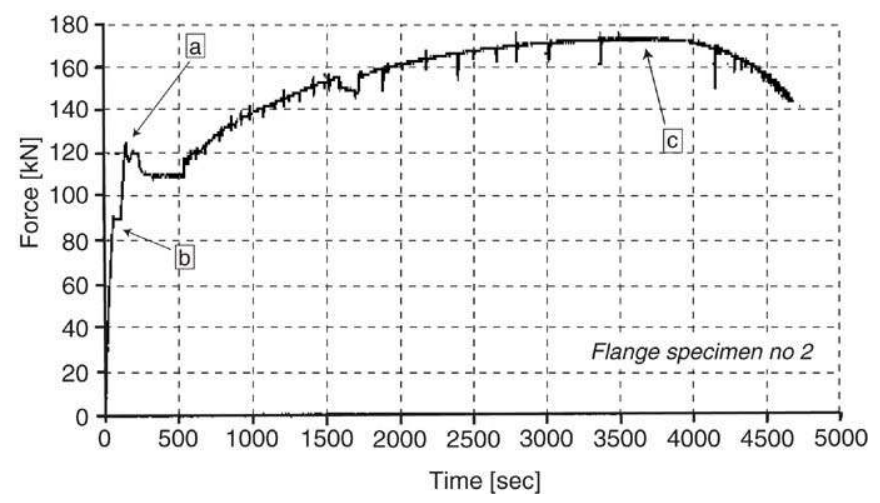

exceed the elastic strain estimated during the material tests, except maybe in the vicinity of the shear studs. Their vertical distribution through the cross-section remained nearly linear with a skip at the steel-concrete interface. Furthermore, the crack widths varied with the loading; they did not seem to 


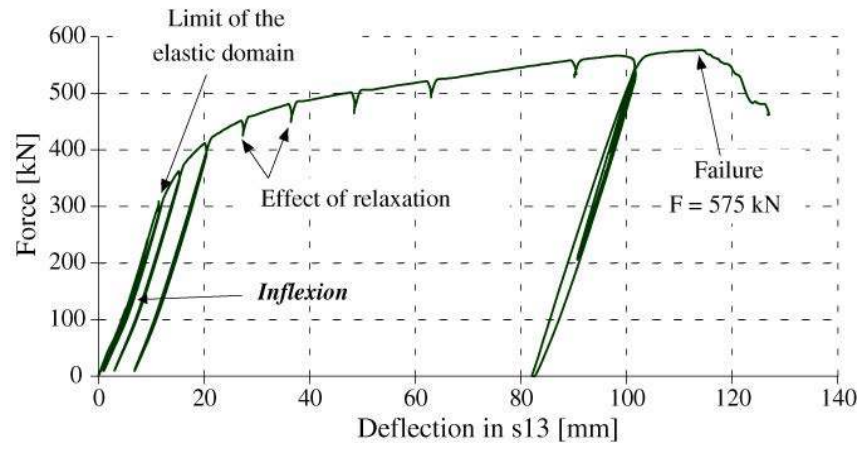

Fig. 7. General behaviour of the composite beam.

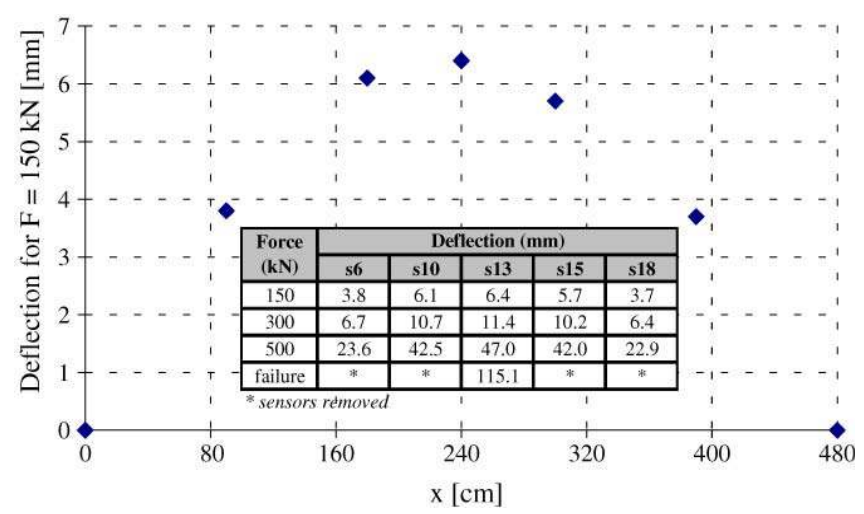

Fig. 8. Longitudinal distribution of the vertical displacement.

Table 5

Crack width (in $\mathrm{mm})^{\mathrm{a}}$

\begin{tabular}{ccrrrr}
\hline Force $(\mathrm{kN})$ & \multicolumn{1}{l}{ T1 } & \multicolumn{1}{l}{ T2 } & \multicolumn{1}{l}{ T3 } & \multicolumn{1}{l}{ T4 } & \multicolumn{1}{c}{ T5 } \\
\hline Initial & 0.20 & 0.08 & 0.10 & 0.20 & 0.18 \\
60 & 0.12 & 0.05 & 0.05 & 0.12 & 0.12 \\
120 & 0.05 & $<0.05$ & $<0.05$ & 0.05 & 0.07 \\
180 & $<0.05$ & $<0.05$ & $<0.05$ & $<0.05$ & $<0.05$ \\
240 & $<0.05$ & $<0.05$ & $<0.05$ & $<0.05$ & $<0.05$ \\
300 & $<0.05$ & $<0.05$ & $<0.05$ & $<0.05$ & $<0.05$ \\
360 & $<0.05$ & $<0.05$ & $<0.05$ & $<0.05$ & $<0.05$ \\
410 & $<0.05$ & $<0.05$ & $<0.05$ & $<0.05$ & $<0.05$ \\
\hline
\end{tabular}

a Average of measures on east and west surfaces.

decrease anymore as the load drops down $180 \mathrm{kN}$; yet it may be noticed that the crack measurements device did not allow us to detect a width lower than $0.05 \mathrm{~mm}$.

The yield domain started at a load of $300 \mathrm{kN}$ as the strain in the central zone of the beam exceeded the linear strain limit of one of the two materials. The measures did not allow us to undoubtedly locate the fibers where non-elastic strain first occurred. Nevertheless, the measurements at section 13 (Fig. 10a and b) indicate that plastic strains first appeared in the upper fiber of the concrete slab at a load of $300 \mathrm{kN}$, whereas yield strain was reached in the lower fiber of the steel beam at a load of $480 \mathrm{kN}$.

Within the yield domain, the plastic strains gradually spread throughout the central zone as the load increased and slowly yielded a hinge length. As a consequence, stress redistribution

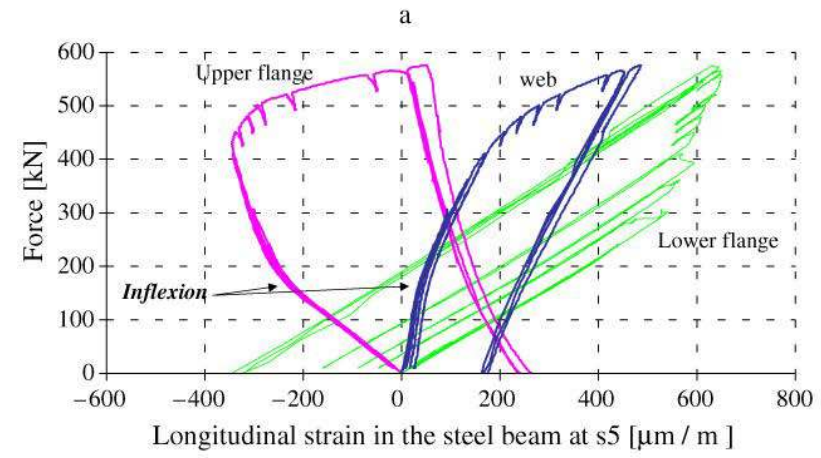

b
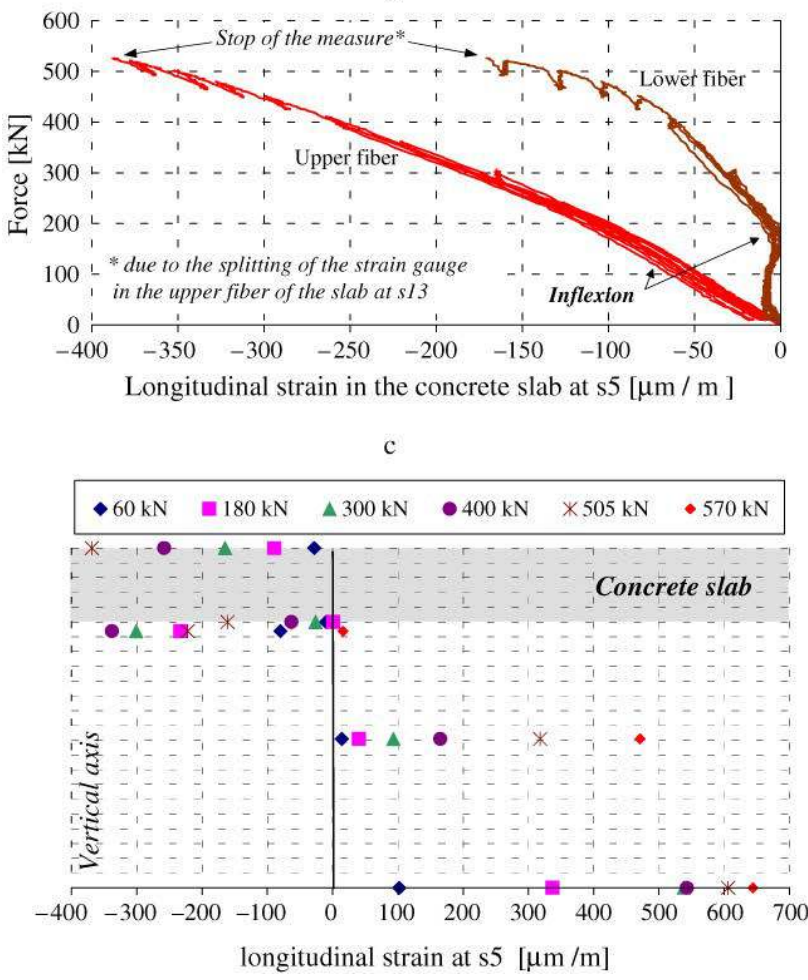

Fig. 9. Strain at section 5 .

occurred along the longitudinal axis and transversally between the concrete slab and the steel beam (sometimes haltingly as illustrated by the small skips observed on force-strain curves). Redistribution may explain the sudden change at $300 \mathrm{kN}$ in the curve related to the web in Fig. 10b though the measured strain was lower than the yield limit.

Consequently, the stiffness of the composite beam continuously decreased within the plastic domain. The ductility was significant and compatible with the structural plastic analysis of modern codes.

Moreover, the vertical distribution of the strain progressively became non-linear in the steel girder and in the concrete slab.

The failure occurred at an ultimate load of $575 \mathrm{kN}$ and corresponded with the sudden decrease of the applied load. It originated in high compressive strength in the top fiber of the concrete slab close to section 15 and was accompanied by crushing. Yield strains occurred in the steel girder up to section 17 . 
a

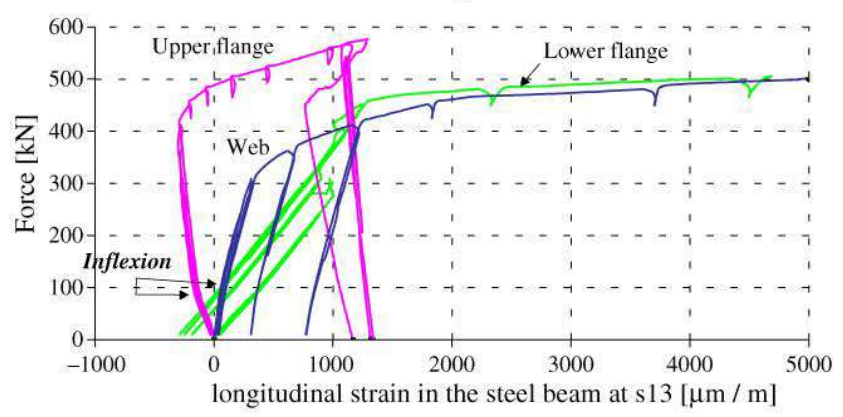

b

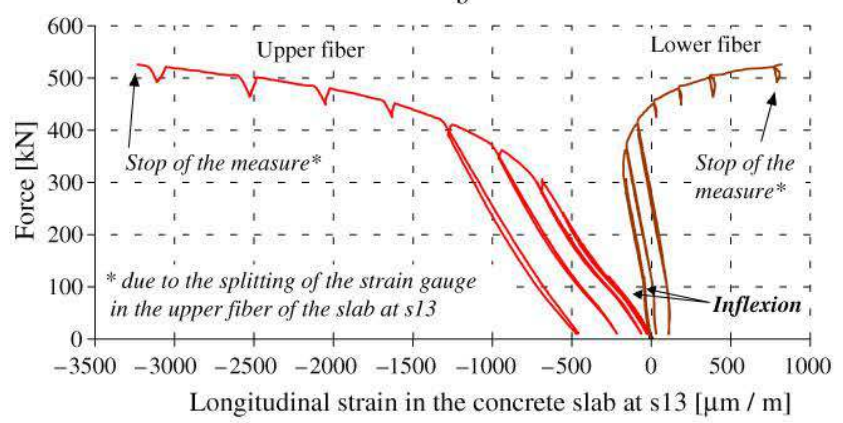

c

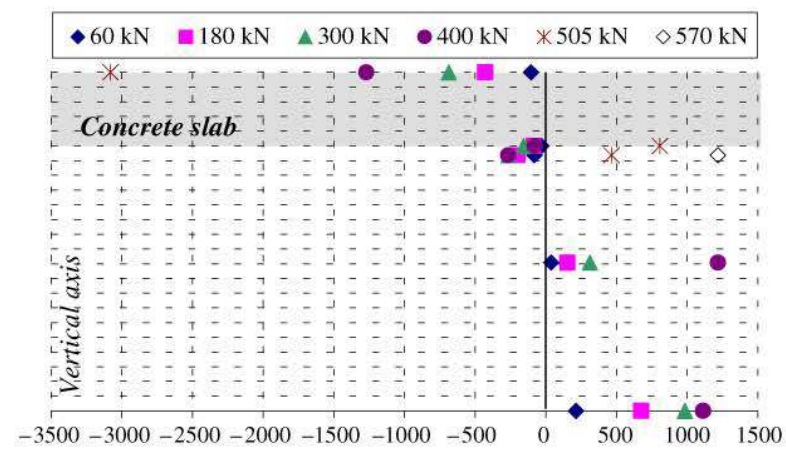

Longitudinal strain at $\mathrm{s} 13$ in the longitudinal axis of the beam $[\mu \mathrm{m} / \mathrm{m}]$

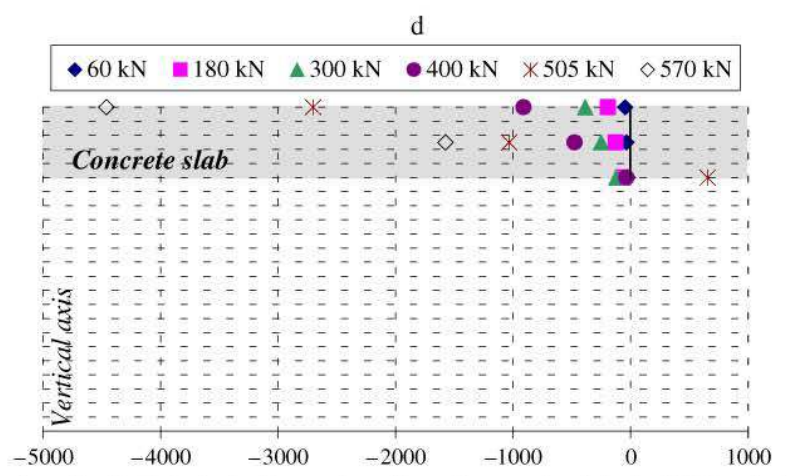

Longitudinal strain in the west surface of concrete slab at s13 $[\mu \mathrm{m} / \mathrm{m}]$

Fig. 10. Strain at section 13 .

\subsubsection{Slip and uplift}

The slip at the steel-concrete interface increased with the load but the maximum value remained low because of the high density of connectors: $0.2 \mathrm{~mm}$ on the elastic domain and $0.8 \mathrm{~mm}$ at the ultimate capacity (see Figs. 12 and 13).

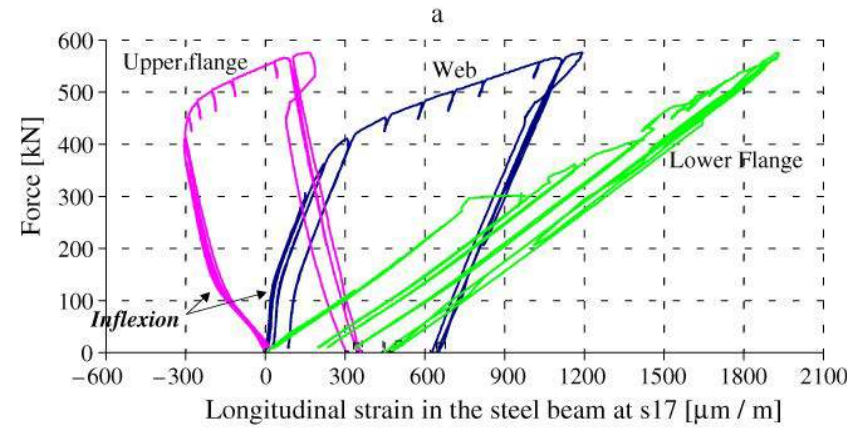

$\mathrm{b}$

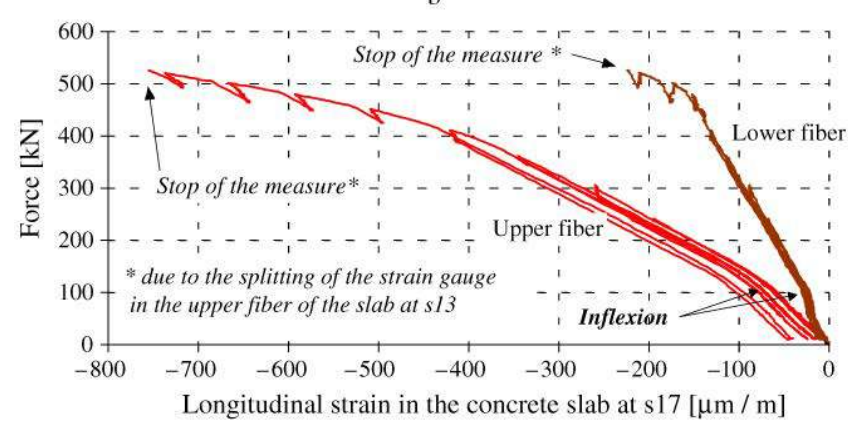

Fig. 11. Strain at section 17.

The longitudinal distribution was somewhat unexpected. First, strong discontinuities may be observed at the instrumented cracks sections. These skips allow considering that cracks divided the composite beam into segments whose slabs were imperfectly connected to each other despite longitudinal reinforcements. The difference between the slip on both sides of a crack suggests that cracks were not completely closed up beyond $180 \mathrm{kN}$.

Furthermore, it may be observed that small slip existed in the central zone of the beam even though the shear force was null, Thus, the longitudinal slip diagram does not only depend on the shear force distribution.

Finally, the maximum slip occurred at a point halfway between the applied force and the support and not at the extremity of the beam as predicted by continuous models [1, 6-8].

\subsubsection{Strains of shear studs}

The analysis of the shear stud axial strains is a more difficult question (see Figs. 14-17). The observations presented below seem never to have been reported before in the literature. It may first be noticed that the yield strain limit (estimated at $2 \%$ ) was never reached. The results shows that the shear studs were horizontally bent, mainly in the longitudinal direction according to the slip movement at the steel-concrete interface.

The deflection pattern of the instrumented stud strongly varied as the load increased and is illustrated in Fig. 18. Up to $180 \mathrm{kN}$, axial strains grew only at the bottom of connectors and corresponded with a cantilever deflection in the direction of the slip (Fig. 18a). Between $180 \mathrm{kN}$ and 300 or $536 \mathrm{kN}$, depending on the shear studs, the bottom strains decreased, changed sign and increased again; the top strains became non-negligible (Fig. 18b). Finally, the shear stud seems to be embedded in the concrete slab as mentioned in previous papers (Fig. 18c). 


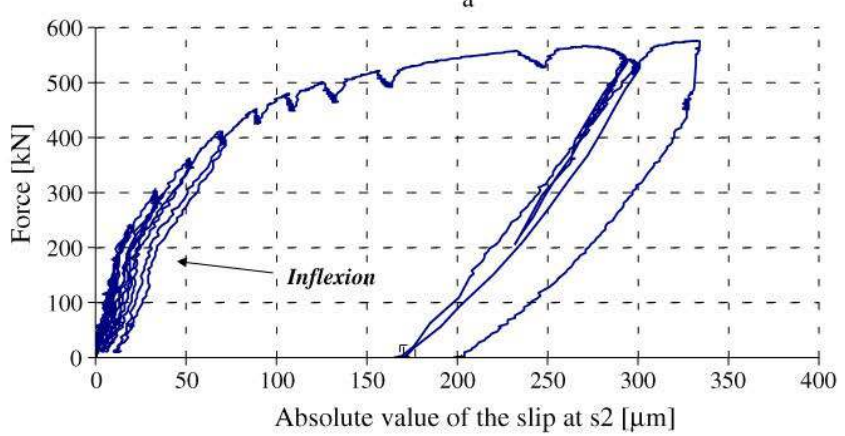

b
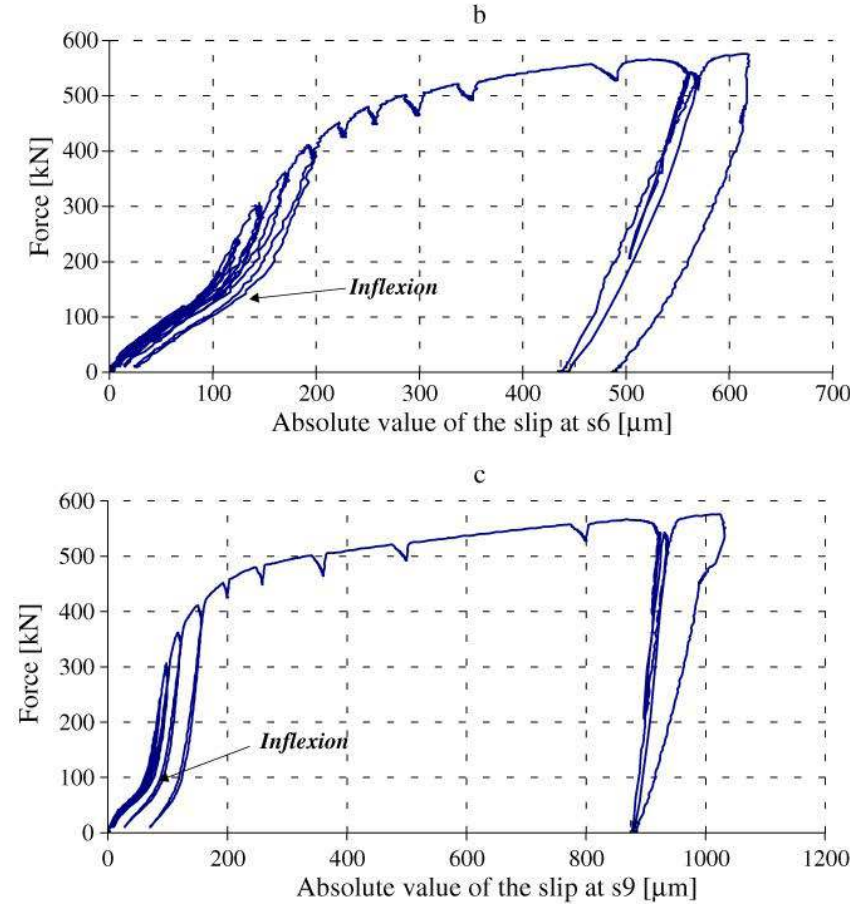

Fig. 12. Slip at sections 2, 6 and 9.

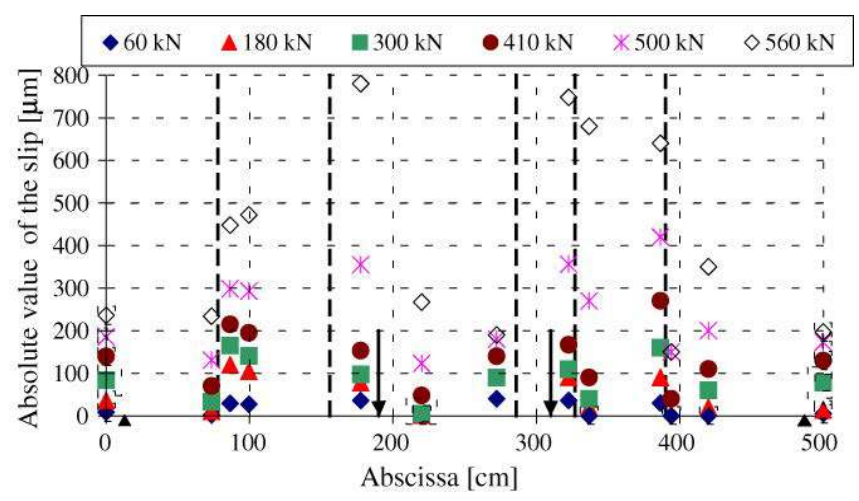

Fig. 13. Longitudinal distribution of the slip.

This evolution of the shear stud curvature may be related to the opening/closing of the transverse cracks as shown in Table 5. It also coincides with the inflexion which may be observed on the force-slip, force-strain and force-deflection curves (see Figs. 7-12). In addition, it may be emphasised that the inflexion points in these graphs occur for a load so much important that the cross-section is close to the supports.

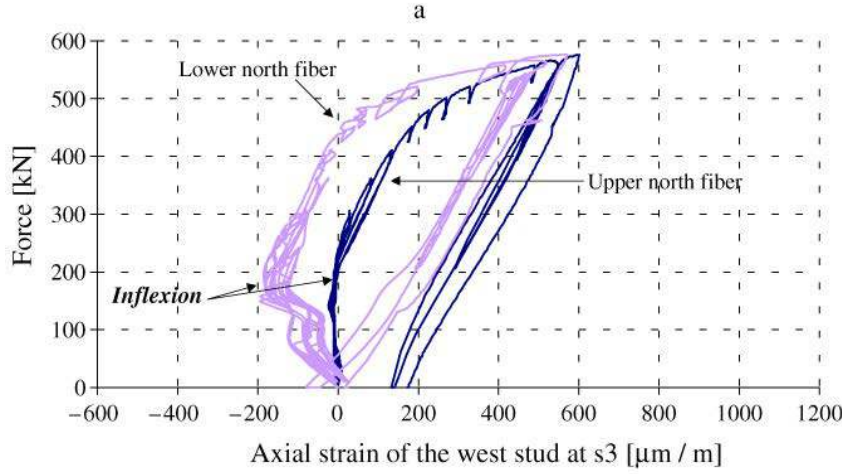

b

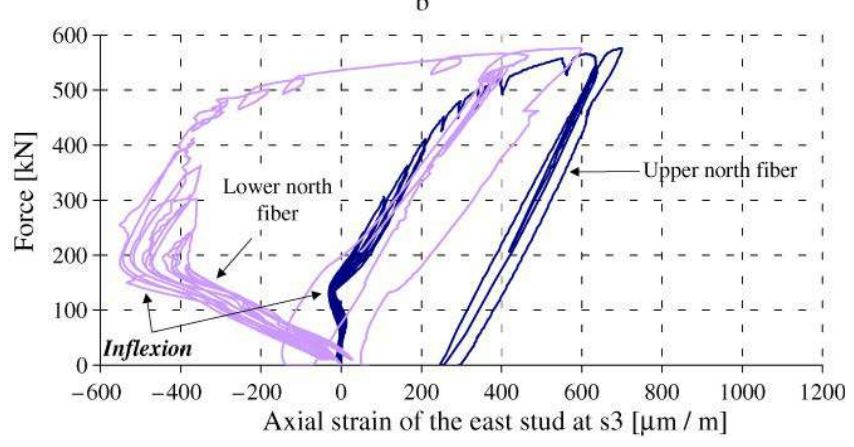

Fig. 14. Strain in studs at section 3 .

Unfortunately, no clear analysis can be provided to explain the different interactions mentioned above.

The strains measured on the east and west sides of the shear studs seem to indicate a very slight bending in the transverse direction. This deflection could also be due to the Poisson effects. Nevertheless, these observations should be confirmed by other specific studies.

Though the experimental results seem to be consistent, it may be noticed that the pressure applied on gages glued on studs could influence the measurements of strain.

\section{Numerical results}

Experimental measurements are hereafter compared with numerical results. Passive reinforcements, shear effects and cracking are neglected.

Within the elastic domain, materials are assumed to behave according to Hooke's law (steel: $E_{\mathrm{s}}=201000 \mathrm{MPa}-$ concrete: $\left.E_{\mathrm{c}}: 33000 \mathrm{MPa}\right)$. Two different model were developed and used: the slip $s$ at the steel-concrete interface is either neglected (perfect bond model according to Eurocode provisions [9]) or accounted for (slip model). In the latter case, the elastic response of a composite beam is governed by a linear second-order differential equation with constant coefficients. The analytical solution could equally be expressed by one of both the following equations $[1,6-8,10]$ :

$$
\begin{aligned}
& N_{c}(x)=A_{N} \operatorname{ch}(\alpha x)+B_{N} \operatorname{sh}(\alpha x)+\frac{\beta}{\alpha^{2}} M(x)+\frac{2 \beta b_{M}}{\alpha^{4}} \\
& s(x)=A_{s} \operatorname{ch}(\alpha x)+B_{S} \operatorname{sh}(\alpha x)-\frac{\beta}{k \alpha^{2}} T(x)
\end{aligned}
$$




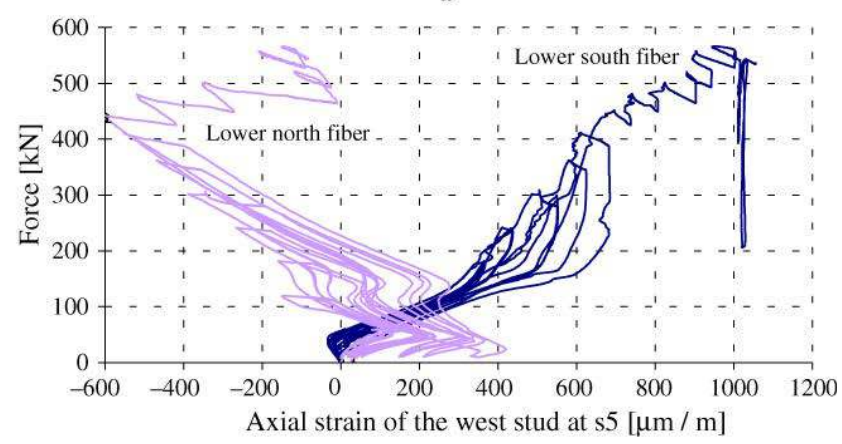

$\mathrm{b}$

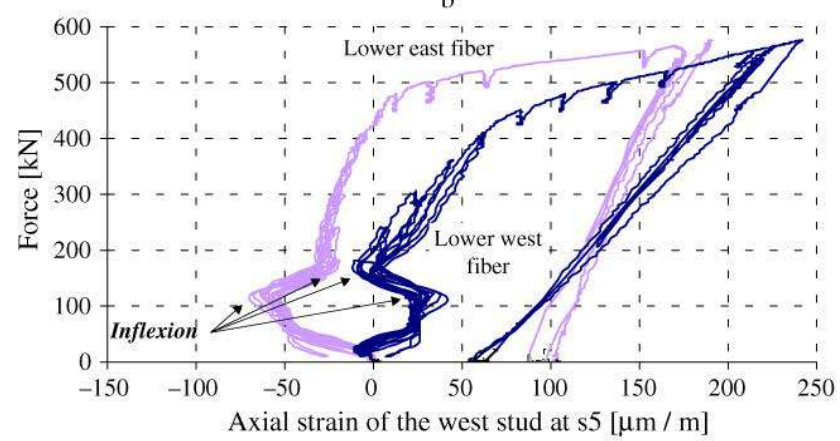

$\mathrm{c}$

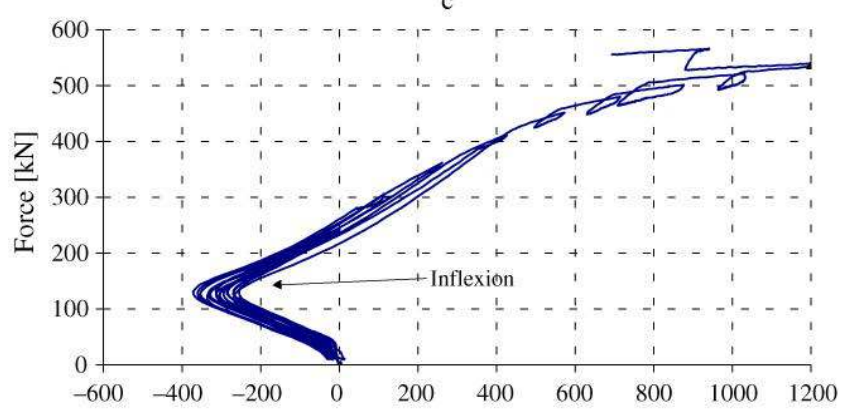

Axial strain in the lower north fiber of the east stud at $s 5[\mu \mathrm{m} / \mathrm{m}]$

Fig. 15. Strain in studs at section 5 .

where $N_{c}$ is the internal axial force in the concrete slab, ch and sh denote hyperbolic cosine and hyperbolic sine respectively, $M(x)=b_{M} x^{2}+c_{M} x+d_{M}$ and $T(x)$ are bending moment and shear respectively, and $\alpha$ and $\beta$ are constants which depend on the geometrical and material characteristics of the composite beam (see referenced papers for more details). The term $k\left[\mathrm{~N} / \mathrm{m}^{2}\right]$ is the stiffness of the connection device, which was determined by means of standard push-out tests [11] and the spacing between connectors: $k=1538 \mathrm{~N} / \mathrm{mm}^{2}$ and $k=667 \mathrm{~N} / \mathrm{mm}^{2}$ in both zones of the beam. The integration constants $\left(A_{N}, B_{N}\right)$ and $\left(A_{s}, B_{S}\right)$ are determined by adequate boundary conditions. As shown in Figs. 19-21, the slip model and the perfect-bond model satisfactorily predict the evolution of deflection and strains. The difference between numerical and experimental deflection should be examined considering that the shear deflection (neglected here) may be estimated at $12 \%$ to $20 \%$ of the bending deflection [12,13]. A significant discrepancy may be noticed between calculated and measured slip close to the end of the beam: this may probably originate in the closing of the cracks. The experimental

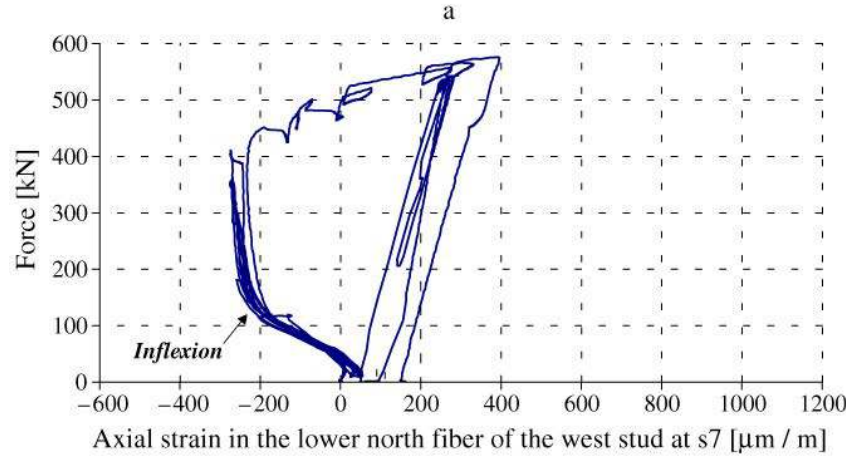

b

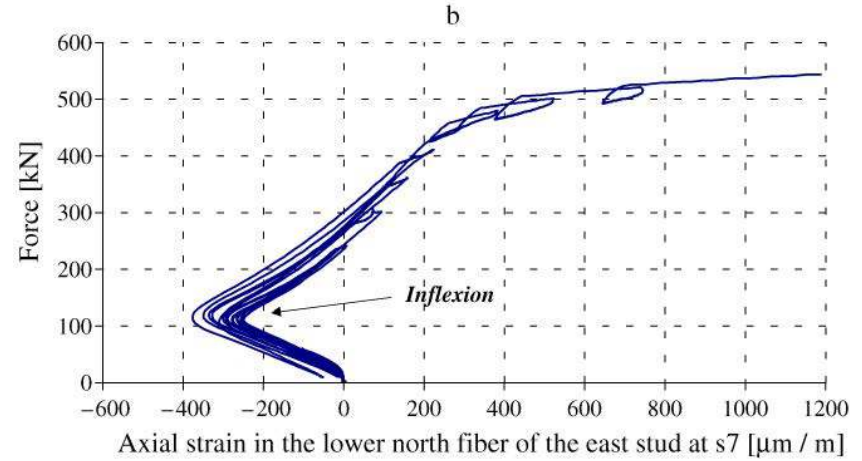

Fig. 16. Strain in studs at section 7.

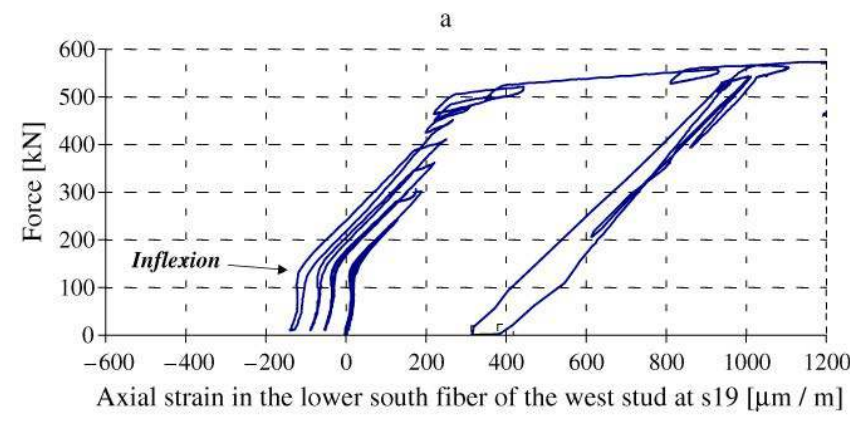

$\mathrm{b}$

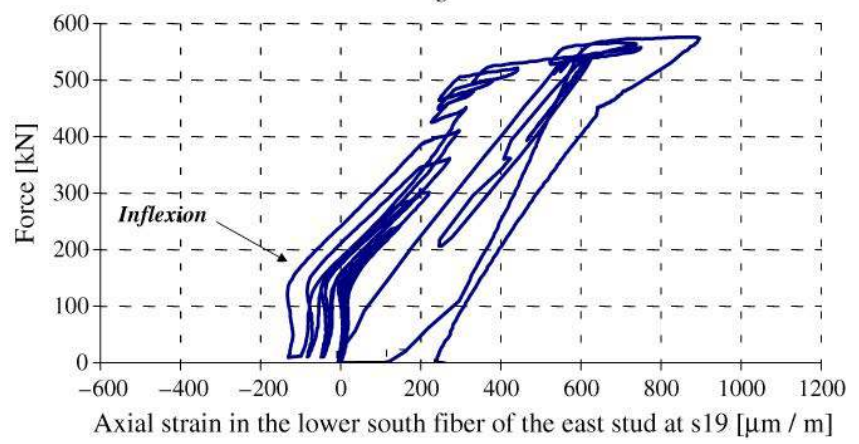

Fig. 17. Strain in studs at section 19.

ultimate load $(575 \mathrm{kN})$ is finally compared with Eurocode provisions. According to this standard, the plastic neutral axis is calculated assuming constant stress within each part of the composite section. Thus, the position of the neutral axis may be determined using the dimensions of the cross-section (see Fig. 1) and the ultimate material characteristics (see Tables 3 and 4). It may be shown that the neutral axis is located at 


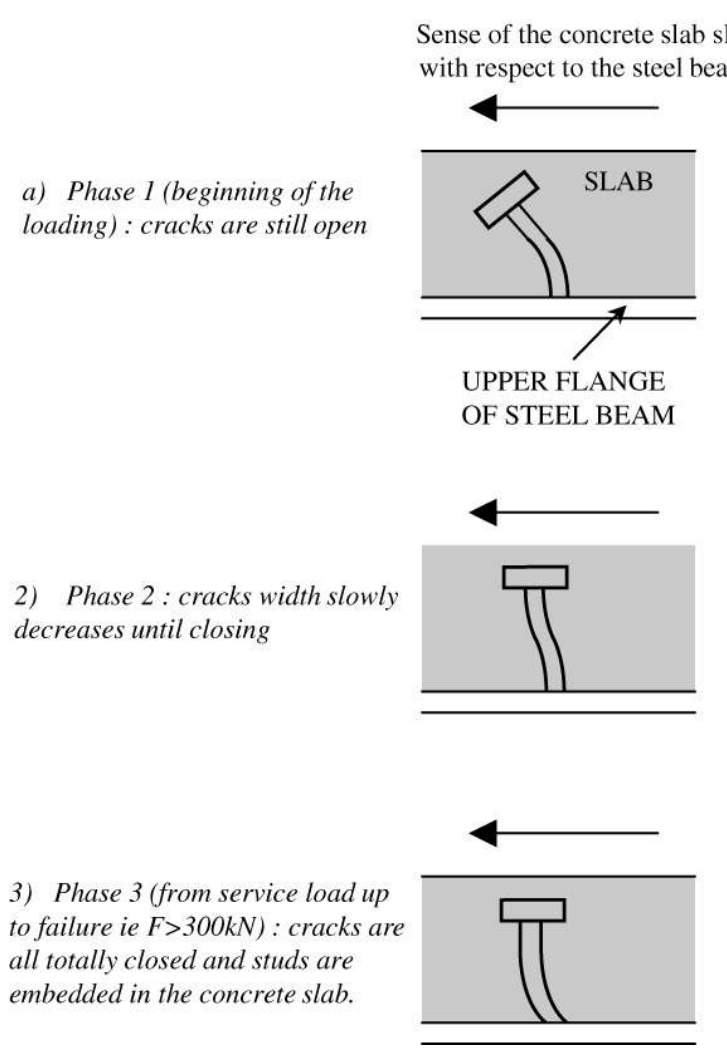

Fig. 18. Strain evolution in studs.

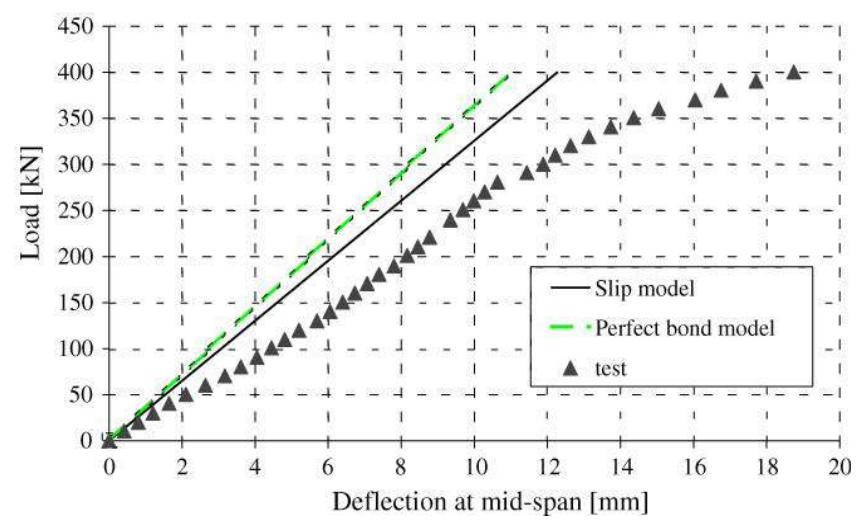

Fig. 19. Deflection at mid-span—experimental versus prediction.

mid-height of the concrete slab assuming a yield strength of $324 \mathrm{MPa}$ and $275 \mathrm{MPa}$ in the web and in the flanges respectively. The plastic moment capacity is then $M_{p l, R d}=$ $494.2 \mathrm{kN} \mathrm{m}$ and the predicted ultimate load is about $550 \mathrm{kN}$, which is close to the experimental value considering that passive reinforcements were neglected.

\section{Conclusions}

The behaviour of a steel-concrete composite beam exhibits an elastic domain and a yield domain with a great ductility. The failure is caused by high compressive stain and crushing of the concrete slab accompanied by plastic strains in the steel girder. Within the elastic phase, the vertical distribution of

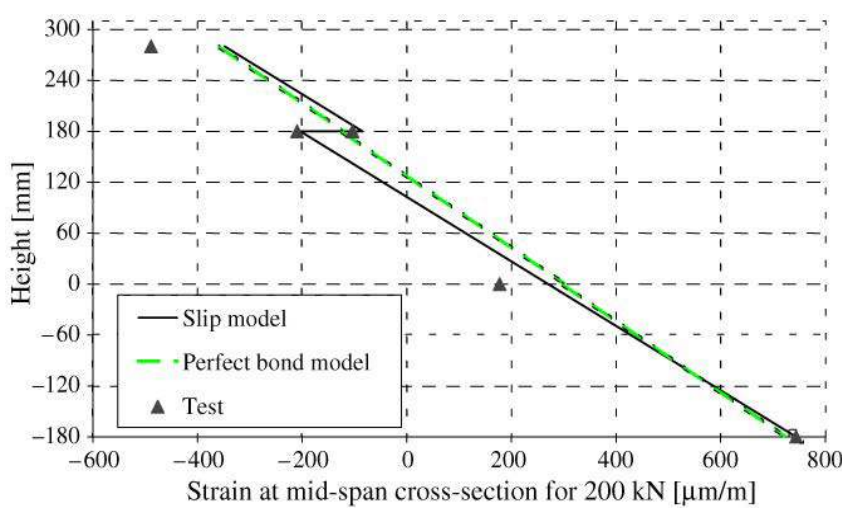

Fig. 20. Strain at mid-span—experimental versus prediction.

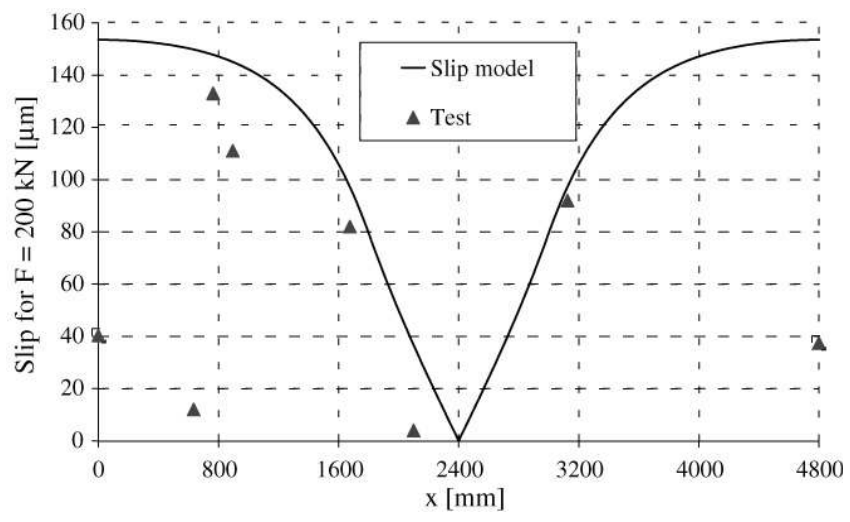

Fig. 21. Longitudinal distribution of the slip-experimental versus prediction.

strain is linear throughout the concrete deck and the steel beam with a discontinuity at their interface. These observations and measurements confirm well-known results.

On the other hand, slip and axial strain of the shear stud measurements seem more interesting as they obviously showed the influence of the initial transverse cracks. Their widths decreased as the load increased and these cracks induced strong discontinuities in the longitudinal distribution of the slip. Moreover the horizontal deflection of the shear studs was significantly modified during the loading. Shear studs seem finally to be imbedded in the concrete slab only if the cracks are (almost) closed. This influence was also noticeable on the strain-stress state of the beam.

Numerical simulations performed within the elastic domain, accounting for slip or not, and at the ultimate stage according to Eurocodes are in good agreement with measurements for deflection and strains: the effect of cracking seems not to influence significantly the main variables of the flexural behaviour of a steel-concrete composite beam. On the other hand, slip and strains in studs highly depend on cracks which have to be taken into account.

The results presented in this study could be useful in understanding detailed aspects of the behaviour of composite beams, especially in the case of pre-cracked concrete slabs, and to validate models. 


\section{References}

[1] Newmark NM, Siess CP, Viest IM. Tests and analysis of a composite beams with incomplete interaction. Proc Soc Exprr Stress Anal 1951;9: 75-92.

[2] Chapman JC, Balakrishnan S. Experiments on composite beams. Struct Eng 1964;42(11):369-83

[3] Aribert JM, Labib AG, Rival JC. Etude numérique et expérimentale de l'influence d'une connexion partielle sur le comportement de poutres mixtes. Journées A.F.P.C., Paris; 1983. p. 69-89.

[4] Adbel Aziz K. Modélisation et étude expérimentale de poutre mixte acierbéton à connexion partielle ou espacée. Thèse de l'INSA de Rennes. 1986.

[5] Nishimura A, Okumura T, Ariga A. Shear connector utilizing the reinforcing steel in composite girder slab. In: 17th national symposium on bridges and structural engineering. Tokyo: Japan Society for the Promotion of Science; December 1971. p. 35-47.

[6] Adekola AO. Interaction between steel beams and concrete slab. Thesis of the Imperial College of Science and Technology. London; 1959.
[7] Adekola AO. Partial interaction between elastically connected elements of a composite beam. Internat J Solids Structures 1968;(4): $1125-1135$.

[8] Lebet JP. Comportement des ponts mixtes acier-béton avec interaction partielle de la connexion et fissuration du béton. Thèse no 661 de l'Ecole Polytechnique Fédérale de Lausanne. 1987.

[9] Eurocode 4 et document d'application national, Conception et dimensionnement des structures mixtes acier-béton - partie 1.1 règles générales et règles pour le bâtiment. Eyrolles, Paris. 1997.

[10] Jurkiewiez B, Buzon S, Sieffert JG. Incremental viscoelastic analysis of composite beams with partial interaction. Comput Struct 2005;83: 1780-91.

[11] Viest IM. Investigations of stud shear connectors for composite concrete and steel T-beams. J Amer Concrete Institute 1956;875-91.

[12] Chapman JC, Balakrishnan S. Experiments on composite beams. Struct Eng 1964;42(11):369-83.

[13] Slutter RG, Driscoll GC. Flexural strength of steel-concrete composite beam. J Struct Division, ASCE 1965;91(ST2):71-99. 